\title{
Incorporating Heteroatoms into Fluorene-Type Conjugated Polymers for Enhanced Photocatalytic Hydrogen Production
}

Received 00th January 20xx, Accepted 00th January 20xx

DOI: $10.1039 / \times 0 \times x 00000 x$
Yang Bai, ${ }^{a}$ Duncan J. Woods, ${ }^{a}$ Liam Wilbraham, ${ }^{b}$ Catherine M. Aitchison, ${ }^{a}$ Martijn A. Zwijnenburg, ${ }^{*, b}$ Reiner Sebastian Sprick, ${ }^{*, a}$ and Andrew I. Cooper*,a

\begin{abstract}
The photocatalytic performance of fluorene-type polymer photocatalysts for hydrogen production from water in the presence of a sacrificial hole scavenger is significantly improved by the incorporation of heteroatoms into the bridge-head. This improvement can be explained by a combination of factors, including changes in thermodynamic driving-force, particle size, dispersibility under photocatalytic conditions, and light absorption.
\end{abstract}

\section{Introduction}

The photocatalytic generation of hydrogen from water by water splitting using sunlight is an important area of research. Most photocatalysts studied are inorganic ${ }^{1-4}$ and the only organic material that has been studied very extensively is carbon nitride. ${ }^{5-8}$ Other $\pi$-conjugated organic materials, such as conjugated linear polymers, ${ }^{9-16}$ conjugated microporous polymers, ${ }^{17-21}$ covalent organic frameworks, ${ }^{22-26}$ and covalent triazine-based frameworks, ${ }^{27-30}$ have also begun to attract attention as organic photocatalysts due to their accessibility via low temperature routes ${ }^{9,31}$ and their synthetic tunability. ${ }^{17}$ It has been found that the incorporation of different but closely related monomer building blocks, such as dibenzo[ $[b, d]$ thiophene and dibenzo[ $[b, d]$ thiophene sulfone, can affect the photocatalytic performance dramatically. ${ }^{32,33}$ With this in mind, we considered the subtle change of the bridging atom in $9 \mathrm{H}$-fluorene-based monomers to heteroatoms other than nitrogen. Previously, the incorporation of different heteroatoms into the bridge-head of fluorene co-polymers was shown to affect the chargetransport in amorphous poly(triarylamine)s, ${ }^{34}$ stacking distances in the solid-state, ${ }^{35}$ and refractive indices. ${ }^{36}$

Here, we explore the effect incorporating tetrels (silicon, germanium), pnictogens (nitrogen, phosphorus) and chalocogens (oxygen, sulfur) of periods 2 to 4 into the $9 \mathrm{H}$ fluorene bridge-head position as alternative bridging atoms. In total, 25 new conjugated polymers were prepared with these heterofluorenes as co-polymers with phenylene, dibenzo[ $[b, d]$ thiophene sulfone, and spirobifluorene. All materials were tested as photocatalysts for hydrogen production from water in the presence of a sacrificial reagent and we found that this subtle change results in significant modulation of the catalytic activity for the materials.

\section{Experimental}

All polymers were synthesized using $\mathrm{Pd}(0)$-catalyzed SuzukiMiyaura polycondensation of diboronic acid esterfunctionalized monomers with bromo-functionalized comonomers (see Supporting Information for synthetic details).9,17 The phenylene co-polymers ${ }^{9}$ (p-XPh, Figure 1), dibenzo $[b, d]$ thiophene sulfone co-polymers ${ }^{13} \quad(\mathbf{p}-\mathbf{X S})$ and spirobifluorene polymers ${ }^{21}$ (X-CMP3) were all insoluble in common organic solvents and in water. Chloroform-soluble polymers ${ }^{37}$ (sP-XS) were obtained by incorporating alkyl sidechains on the bridge-head atom. The materials were characterized by UV-vis spectroscopy (Fig. S-10 to Fig. S-20) and elementary analysis. Thermogravimetric analysis (TGA) indicated that all polymers were thermally stable in air up to $300{ }^{\circ} \mathrm{C}$ (Fig. S-67 to Fig. S-69), and PXRD patterns showed that all linear polymers were semi-crystalline, except for $\mathbf{p}$-POPh and X-CMP3 materials, which were amorphous (Fig. S-31 to Fig. S-33). The potentials of the charge carriers in the different polymers were estimated using our standard approach ${ }^{38,39}$ based on $\triangle \mathrm{DFT}$ calculation using the B3LYP40,41 density functional on a single polymer chain immersed in a dielectric continuum with $\varepsilon_{\mathrm{r}} 80.1$ (water).

\footnotetext{
a. Department of Chemistry and Material Innovation Factory, University of Liverpool, Crown Street, Liverpool L69 7ZD, U. K. E-mail: ssprick@liverpool.ac.uk aicooper@liverpool.ac.uk

b. Department of Chemistry, University College London, 20 Gordon Street, London WC1H OAJ, U.K. E-mail: m.zwijnenburg@ucl.ac.uk

Electronic Supplementary Information (ESI) available: [details of any supplementary information available should be included here]. See DOI: $10.1039 / x 0 x \times 00000 x$
} 
a)

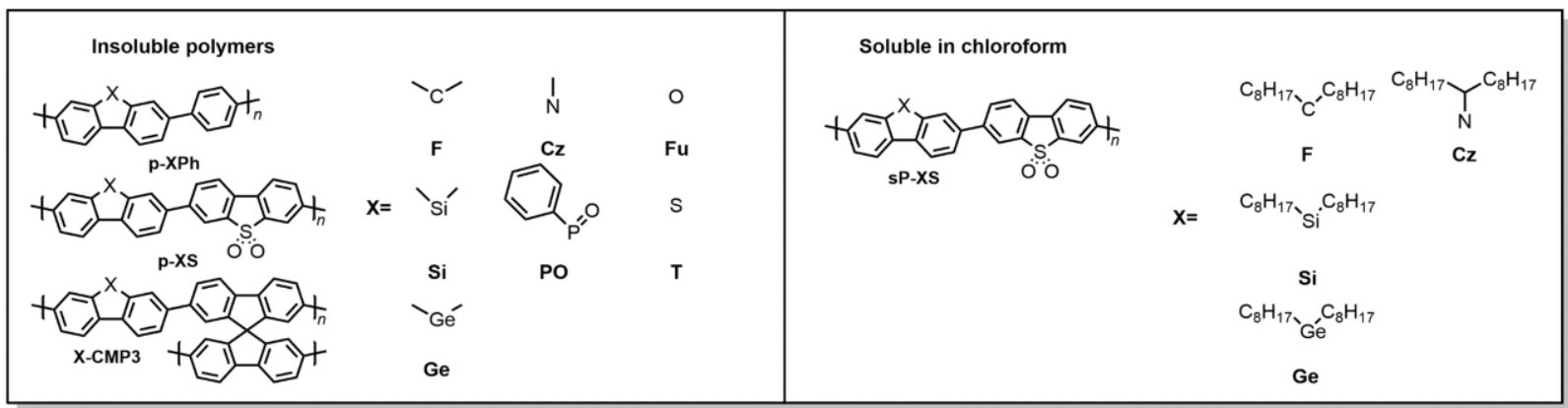

b)
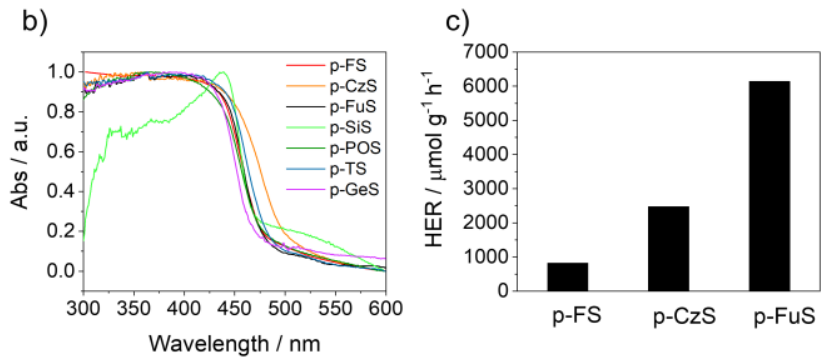

d)

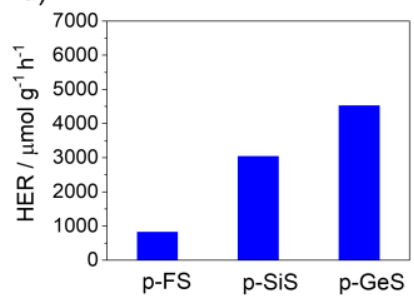

e)

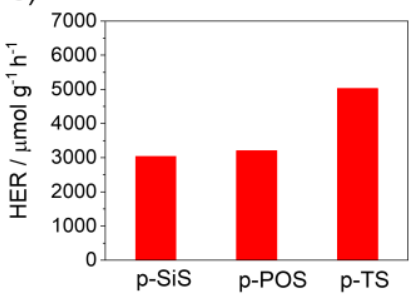

Fig. 1 a) Structures of the polymer photocatalysts in this study; b) UV/vis spectra of the 7 dibenzo[ $b, d]$ thiophene sulfone-containing photocatalysts, as measured in the solid state; hydrogen evolution rates of c) p-FS, p-CzS and p-FuS; d) p-FS, p-SiS and p-GeS; e) p-SiS, p-POS and p-TS under visible-light irradiation ( $\lambda>420$ nm, $300 \mathrm{~W}$ Xe light source).

\section{Results and discussion}

All of the materials in this series (Fig. 1) acted as photocatalysts for hydrogen evolution from water/triethylamine/methanol mixtures. Triethylamine (TEA) was used as the hole-scavenger, ${ }^{9,16}$ while methanol was added to aid mixing of the TEA with water.9,17 The measured hydrogen evolution rates (HERs) under visible light ( $\lambda>420 \mathrm{~nm}, 300 \mathrm{~W}$ Xe light source) ranged from $128 \mu \mathrm{mol} \mathrm{g}^{-1}$ $\mathrm{h}^{-1}$ to $5882 \mu \mathrm{mol} \mathrm{g}{ }^{-1} \mathrm{~h}^{-1}$, with photocatalyst $\mathrm{p}$-FuS being found to be the most active of the polymers in this study (Table 1). The hydrogen evolution rate for p-FuS is approximately $17 \%$ higher than our previously reported dibenzo $[b, d]$ thiophene sulfone co-polymer p-TS (P1-64) under the same conditions (5026 $\mu_{\mathrm{mol} \mathrm{g}}{ }^{-1} \mathrm{~h}^{-1}$ ) (Table 1). ${ }^{32,33}$ Similarly, the phenylene copolymer p-POPh $\left(2636 \mu \mathrm{mol} \mathrm{g}^{-1} \mathrm{~h}^{-1}\right)$ is around twice as active as P7 (1492 $\mu \mathrm{mol} \mathrm{g}^{-1} \mathrm{~h}^{-1}$ ) (Table 1), which was among the most photocatalytically-active phenylene co-polymers reported previously. ${ }^{11,13}$ Comparing the different families of polymers reported here, the $\mathbf{p}$-XS family is the most active, followed by the $\mathbf{p - X P h}$ family and the X-CMP3 networks, while the sp-XS family of soluble co-polymers are the least active, possibly due to poorer wetting through the incorporation of the solubilizing alkyl side-chains (Fig. S-102). ${ }^{37}$

We next tried to correlate the observed hydrogen evolution rates with a range of different measured and predicted polymer properties: we focused in this comparison on copolymers in the $\mathbf{p}$-XPh and $\mathbf{p}$-XS families because they allow for the most like-for-like comparison. In previous work, ${ }^{30,32}$ we found that the key properties to consider are the optical gap, the wavelength below which the polymer starts absorbing light (Fig. 1b), ${ }^{17}$ the thermodynamic potentials of charge-carriers of the material (Fig. 2), ${ }^{14}$ and the dispersibility of the polymer in the reaction medium. ${ }^{13}$ We therefore started by considering the same factors here. All polymers studied can absorb visible

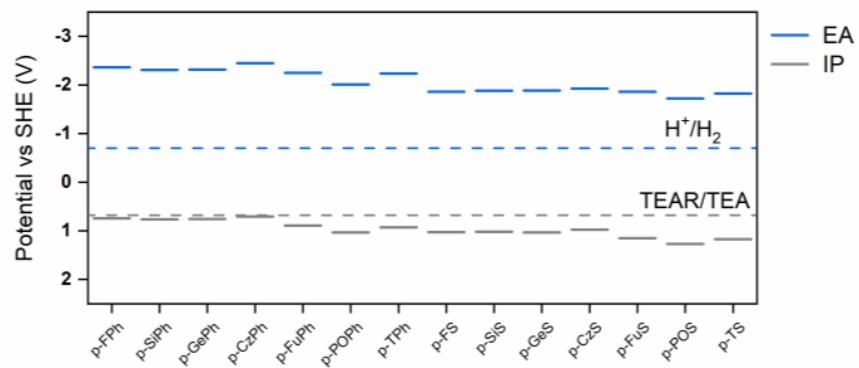

Fig. 2 Ionization potentials and electron affinities of the different photocatalysts as predicted using DFT, as well as the potentials of the different solution reactions at $\mathrm{pH}$ 11.5, the likely $\mathrm{pH}$ of a TEA solution (TEAR is the deprotonated TEA radical $\mathrm{N}(\mathrm{Et})_{2} \mathrm{CHCH}_{3}$ ). Potential for the overall oxidation of TEA to diethylamine (DEA) and acetaldehyde (ACO) is not shown because it lies at a similar value to the $\mathrm{H}^{+} / \mathrm{H}_{2}$ potential; the potential for the oxidation of TEAR to DEA and AcO is not shown since it is more negative than $-3 \mathrm{~V}$. 
light because they all have optical gaps that are smaller than $2.95 \mathrm{eV}(\lambda>420 \mathrm{~nm})$. The optical gap varies little within families of polymers, but considerably between the families. Most notably, the optical gap of the p-XS polymers is redshifted relative to the $\mathbf{p}$-XPh polymers, probably because of the more planar structure of the former. ${ }^{9}$ The polymers with the highest hydrogen evolution rates are those with the smallest optical gaps (Fig. 3a) and the envelope that encloses all the points shows that the hydrogen evolution rate clearly Table 1. Photophysical properties and hydrogen evolution rates (HERs) for the polymer photocatalysts.

\begin{tabular}{|c|c|c|c|c|c|c|c|c|}
\hline & $\begin{array}{c}\text { Photocatal } \\
\text { yst }\end{array}$ & $\begin{array}{c}\text { Optical } \\
\text { gap } \\
{[e V]^{a}}\end{array}$ & $\begin{array}{c}\tau_{\text {avg }} \\
{[n s]^{b}}\end{array}$ & $\begin{array}{c}\text { Particle } \\
\text { size } \\
{[\mu \mathrm{m}]^{c}} \\
\end{array}$ & $\begin{array}{c}S A_{\mathrm{BET}} \\
{\left[\mathrm{m}^{2} \mathrm{~g}^{-1}\right]^{\mathrm{d}}}\end{array}$ & $\begin{array}{c}\text { Transmission } \\
{[\%]^{\mathrm{e}}}\end{array}$ & $\begin{array}{c}\text { HER } \lambda>420 \mathrm{~nm} \\
{\left[\mu \mathrm{mol} \mathrm{h}{ }^{-1} \mathrm{~g}^{-1}\right]^{\mathrm{f}}}\end{array}$ & $\begin{array}{c}\text { HER } \lambda>295 \mathrm{~nm} \\
{\left[\mu \mathrm{mol} \mathrm{h}-1 \mathrm{~g}^{-1}\right]^{\mathrm{f}}}\end{array}$ \\
\hline \multirow{7}{*}{ 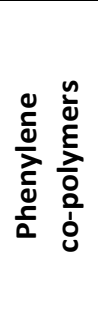 } & p-FPh & 2.79 & 2.50 & 2.94 & 4 & 22.5 & $136( \pm 4)$ & $708( \pm 4)$ \\
\hline & $\mathrm{p}-\mathrm{Cz} \mathrm{Ph}$ & 2.72 & 0.54 & 2.53 & 14 & 76.3 & $128( \pm 4)$ & $568( \pm 8)$ \\
\hline & p-FuPh & 2.77 & 0.18 & 2.75 & 35 & 2.0 & $1925.6( \pm 23)$ & $3259.3( \pm 183)$ \\
\hline & p-SiPh & 2.89 & 0.39 & 7.76 & 55 & 0.7 & $199.8( \pm 47)$ & 1544.0 ( \pm 139$)$ \\
\hline & p-POPh & 2.74 & 0.54 & 2.82 & 27 & 58.7 & $2635.9( \pm 98)$ & $3641.3( \pm 277)$ \\
\hline & p-TPh & 2.79 & 0.26 & 2.1 & 29 & 2.3 & $432.0( \pm 4)$ & $1660.0( \pm 12)$ \\
\hline & p-GePh & 2.85 & 0.19 & 2.69 & 6 & 48.6 & $544.6( \pm 115)$ & $1446.4( \pm 98)$ \\
\hline \multirow{7}{*}{ 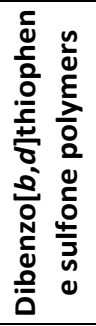 } & p-FS & 2.59 & 0.46 & 8.28 & 114 & 0.2 & $826( \pm 38.8)$ & $1545( \pm 75.9)$ \\
\hline & p-CzS & 2.44 & 4.51 & 3.46 & 3 & 34.8 & $2477.6( \pm 44)$ & 2954.1 ( \pm 159$)$ \\
\hline & p-FuS & 2.57 & 2.54 & 0.87 & 67 & 0.4 & $5882.4( \pm 253)$ & $8371.6( \pm 500)$ \\
\hline & p-SiS & 2.66 & 1.07 & 3.53 & 5 & 54.1 & $2893.4( \pm 224)$ & $3431.8( \pm 156)$ \\
\hline & p-POS & 2.58 & 0.52 & 1.76 & 9 & 42.3 & $3209.1( \pm 145)$ & $3242.7( \pm 355)$ \\
\hline & p-TS & 2.56 & 2.26 & 2.63 & 127 & 5.1 & $5026.2( \pm 212)$ & $10276.0( \pm 577)$ \\
\hline & p-GeS & 2.63 & 0.60 & 2.3 & 30 & 0.3 & $4520.8( \pm 127)$ & $9949.2( \pm 560)$ \\
\hline \multirow{7}{*}{ 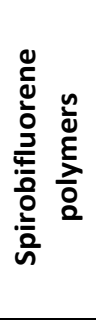 } & F-CMP3 & 2.77 & 0.35 & 6.31 & 596 & 0.4 & $538( \pm 32.0)$ & $2544( \pm 21.5)$ \\
\hline & Cz-CMP3 & 2.72 & 0.17 & 4.81 & 422 & 4.0 & $439.2( \pm 31)$ & $703.7( \pm 24)$ \\
\hline & Fu-CMP3 & 2.80 & 0.22 & 10.7 & 513 & 3.6 & $601.3( \pm 22)$ & $1875.6( \pm 125)$ \\
\hline & Si-CMP3 & 2.81 & 0.47 & 5.66 & 566 & 74.1 & $121.7( \pm 9)$ & $1121.5( \pm 59)$ \\
\hline & PO-CMP3 & 2.64 & 0.28 & 3.4 & 153 & 0.3 & $2413.1( \pm 97)$ & $2606.4( \pm 113)$ \\
\hline & T-CMP3 & 2.78 & 0.22 & 5.22 & 508 & 13.9 & $489.0( \pm 22)$ & $1663.6( \pm 125)$ \\
\hline & Ge-CMP3 & 2.70 & 0.36 & 8.81 & 653 & 5.4 & $189.4( \pm 16)$ & $611.2( \pm 19)$ \\
\hline \multirow{4}{*}{$\frac{0}{\frac{0}{0}} \frac{n}{\frac{0}{2}}$} & SP-FS & 2.80 & 0.48 & 9.86 & $-[i]$ & 75.3 & $682.0( \pm 35)$ & n.d. ${ }^{[i]}$ \\
\hline & sP-CzS & 2.76 & 0.21 & 3.05 & $-[i]$ & 34.6 & $649.0( \pm 98)$ & n.d. ${ }^{[i]}$ \\
\hline & sP-SiS & 2.79 & 0.75 & 24.3 & $-[i]$ & 54.1 & $1936.0( \pm 326)$ & n.d..$^{[i]}$ \\
\hline & sP-GeS & 2.90 & 0.60 & 179 & $-[i]$ & 79.1 & $0.7( \pm 0.08)$ & n.d..$^{[i]}$ \\
\hline
\end{tabular}

a) Optical gap calculated from the absorption on-set; b) Estimated weighted average life-time of the excited state determined by time-correlated single-photon counting; c) Surface area mean diameter (Sauter mean diameter); d) Apparent BET surface area calculated from the $\mathrm{N}_{2}$ adsorption isotherm; e) Average transmittance of a polymer suspension in water/methanol/trimethylamine $(1: 1: 1) ;{ }^{\text {f) }}$ Reaction conditions: $25 \mathrm{mg}$ polymer was suspended in $25 \mathrm{~mL}$ water/methanol/triethylamine (1:1:1) solution, irradiated by $300 \mathrm{~W}$ Xe light source using suitable filters; i) Not determined.

driving force for the first one-hole oxidation step of TEA (Fig. 3c). As can be seen from Fig. 3c, when considering the envelope that encloses all polymers, the hydrogen evolution rate increases, in general, when the polymer's predicted IP becomes more positive and the driving force for the one-hole and, hence, overall oxidation of TEA increases. By contrast, as can be seen from Fig. $3 b$, the hydrogen evolution rate decreases when the polymer's predicted EA becomes more negative and the driving force for proton reduction increases. This, while apparently counter-intuitive, suggests that the rate increases with decreasing optical gap. All polymers were estimated to have a very negative electron affinity (EA) and a significantly positive ionization potential (IP). As results the polymers should have ample driving force for proton reduction (Fig. 3b), significant driving force for the overall TEA oxidation to diethylamine and acetaldehyde and a negligible to moderate 
the water/methanol/TEA mixture used for photocatalysis experiments (transmittance $\sim 0 \%$; Fig. $3 d$ ). There is a clear downward trend in the hydrogen evolution rate with increasing transmittance and, hence, decreasing dispersibility. A plot of the hydrogen evolution rate against the average particle-size, as measured by static light scattering (SLS) (Fig. 3e), suggests that this might be an important factor in the dispersibility, since the most dispersible polymers also tend to have the smaller average particles (Fig. S-61). Scanning electron microscopy (SEM) of the p-FuS (Fig. S-62) showed morphologies that agreed well with the DLS measurements. a)

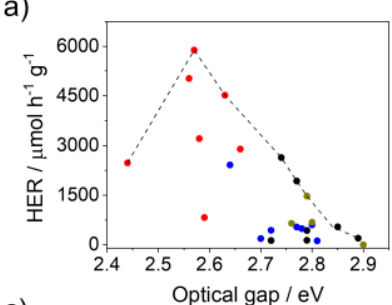

c)

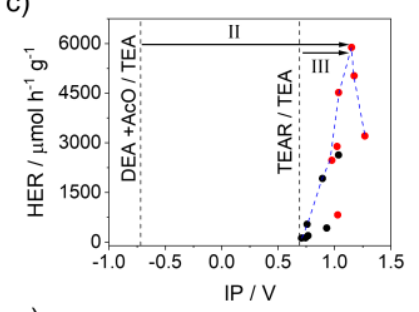

e)

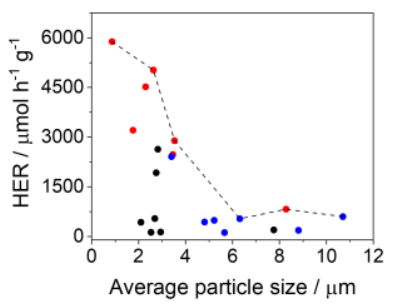

b)

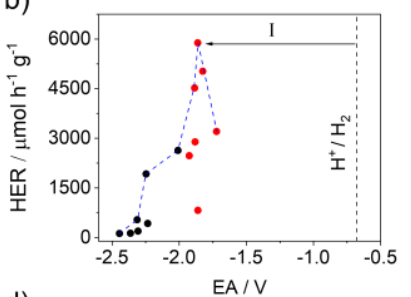

d)

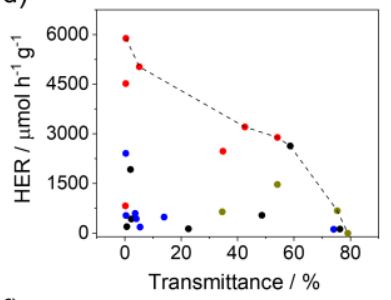

f)

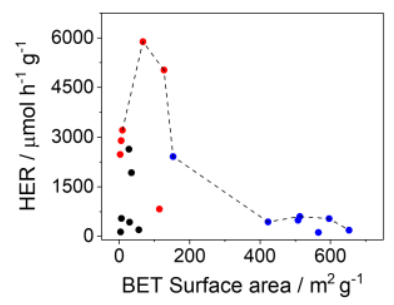

Fig. 3 Photocatalytic hydrogen evolution rates (HER) of the phenylene co-polymers (black), sulfone co-polymers (red), conjugated microporous polymers (blue), and soluble polymers (dark yellow) in TEA/MeOH/ $\mathrm{H}_{2} \mathrm{O}$ mixture under a visible light plotted versus b) predicted EA of photocatalysts, with driving force for proton reduction shown as arrow I; c) predicted IP of photocatalysts, with driving force for the overall oxidation of TEA shown as arrow II and driving force for the one-hole oxidation of TEA shown as arrow III; d) optical gaps of photocatalysts (see Fig. S102 for the equivalent plot using predicted rather than measured values); e) light transmission of the photocatalysts dispersed in TEA/MeOH/ $\mathrm{H}_{2} \mathrm{O}$; f) particle size of the photocatalyst in TEA $/ \mathrm{MeOH} / \mathrm{H}_{2} \mathrm{O} ; \mathrm{g}$ ) BET surface area. The dotted lines on graphs $b$ ) to $g$ ) are envelopes that trace the maximum HER observed across each property range.

By contrast, much larger internal surface area seems to have a negative effect on the catalytic performance of these materials (Fig. 3f). This may be due to the generally poor wettability of these materials and a lack of water penetration into these rather non-polar CMPs. Also, the low physical density of these amorphous microporous polymers might reduce charge transport to a degree that offsets any mass transport benefits associated with high surface areas.

The wettability of the dibenzo[ $[b, d]$ thiophene sulfone copolymers, another potential contributor to the dispersibility of the polymers, was studied by contact angle measurements with water (Fig. S-63 and Fig. S-64). The contact angles against water for these polymers ranged from $52.8^{\circ}$ to $85.0^{\circ}$, with $\mathbf{p}$ POS being the most hydrophilic polymer, and p-GeS being the most hydrophobic polymer. In contrast to the particle size, the contact angles do not correlate well with the dispersibility (Fig. S-65) or hydrogen evolution rate (Fig. S-66), suggesting that small particle-size trumps wettability for these materials, though this might be different If the same polymers could be prepared with different particle size distributions.

Residual Pd within these materials acts as the co-catalyst was studied in previous studies. ${ }^{18,21}$ All insoluble polymers were found to have residual amounts of Pd from the synthesis (ranging from 0.25 wt. \% to $1.72 \mathrm{wt} . \%$ ), while soluble polymers contained less residual Pd (ranging from 0.052 wt. \% to 0.17 wt. \%). Therefore, a Pd content control experiment was performed for the soluble polymer with the highest photocatalysis activity, sP-SiS (Fig. S-95). A loading of 1 wt. \% of $\mathbf{P d}$ for SP-SiS gave a higher hydrogen evolution rate compared with the rate of SP-SiS without Pd loading, but the dependency on Pd concentration was relatively small, with

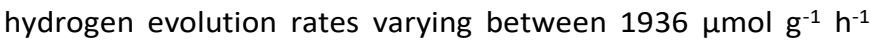
(without additional co-catalyst) and $2370 \mu \mathrm{mol} \mathrm{g}^{-1} \mathrm{~h}^{-1}$ (loaded with 1 wt. \% Pd).

We also considered some other properties, such as the lifetime of the excited-state of the polymer in the reaction mixture as estimated using time-correlated single photon counting (TCSPC, Fig. S-43 to S-56) and the Brunauer-EmmettTeller surface area ( $S A_{\mathrm{BET}}$ ) (Fig. 3f).

As observed in our previous work, the hydrogen evolution rate appears to correlate with a combination of contributing factors. A material that has an 'optimal' value for only one property-for example, low transmittance/high dispersibilityis not necessarily catalytically active. For example, p-FS disperses very well in the reaction mixture, but it also has one of the least positive IP values within the $\mathbf{p}$-XS family, and an optical gap value that is larger than more active catalysts such as $\mathbf{p}-\mathbf{C z} \mathbf{S}$ - hence, its photocatalytic activity is low.

To evaluate the stability of these new photocatalysts, we studied the dibenzo[ $[b, d]$ thiophene sulfone-dibenzo $[b, d]$ furan co-polymer (p-FuS) with repeat catalytic runs under visible irradiation ( $300 \mathrm{~W}$ Xe light source, $\lambda>420 \mathrm{~nm}$ ) over a total of 30 hours, with intermittent degassing and replacement of the water/MeOH/TEA mixture after 19 hours. The HER was reduced by about $10 \%$ after 10 hours, but the material was still active when irradiation was continued for a total of 30 hours (Fig. S-98). The material did not show any changes in its UV/vis, photoluminescence, or FT-IR spectrum after 30 hours of irradiation (Fig. S-100 and Fig. S-101). 


\section{Conclusions}

Substitution of the heteroatom in the bridge-head of the fluorene-type copolymers leads to some of the highestperforming polymer photocatalysts that we have found so far. It is somewhat surprising that such a small structural change results in such a significant increase in catalytic activity. This enhanced performance results from the net influence of a number of factors, rather than one single, dominant variable. Our data suggest that particle size plays a role, but there is a degree of correlation between particle size and dispersibility, so it is unclear whether this is connected to external surface area in the photocatalyst, better dispersibility, or both. Though the large internal surface areas of the CMPs seems to have a negative effect on the catalytic performance of these materials. While the soluble polymers were somewhat less catalytically active than the most active insoluble polymers, such as p-FuS, solution processability offers significant potential advantages in terms of device fabrication - for example, in terms of large area devices or solution processing to create artificial Z-schemes or heterojunctions. In this respect, we note that the soluble silole polymer, sP-SiS, has an initial catalytic activity that is significantly higher than its fluorene and carbazole analogues.

$$
\text { . }
$$

\section{Acknowledgements}

We thank the Engineering and Physical Sciences Research Council (EPSRC) for financial support under grant EP/N004884/1. YB thanks the CSC for a scholarship.

\section{Notes and references}

1 A. Kudo and Y. Miseki, Chem. Soc. Rev., 2009, 38, 253-278.

2 S. Chen, T. Takata and K. Domen, Nat. Rev. Mater., 2017, 2, 17050 .

3 T. Jafari, E. Moharreri, A. Amin, R. Miao, W. Song and S. Suib, Molecules, 2016, 21, 900.

4 Q. Wang and K. Domen, Chem. Rev., 2019, DOI: 10.1021/acs.chemrev.9b00201.

5 X. Wang, K. Maeda, A. Thomas, K. Takanabe, G. Xin, J. M. Carlsson, K. Domen and M. Antonietti, Nat. Mater., 2009, 8, 76-80.

6 Z. Zhao, Y. Sun and F. Dong, Nanoscale, 2015, 7, 15-37.

7 J. Wen, J. Xie, X. Chen and X. Li, Appl. Surf. Sci., 2017, 391, 72-123.

8 Y. Wang, A. Vogel, M. Sachs, R. S. Sprick, L. Wilbraham, S. J. A. Moniz, R. Godin, M. A. Zwijnenburg, J. R. Durrant, A. I. Cooper and J. Tang, Nat. Energy, 2019, 4, 746-760. R. S. Sprick, B. Bonillo, R. Clowes, P. Guiglion, N. J. Brownbill, B. J. Slater, F. Blanc, M. A. Zwijnenburg, D. J. Adams and A. I. Cooper, Angew. Chem. Int. Ed., 2016, 55, 1792-1796.

10 K. Zhang, D. Kopetzki, P. H. Seeberger, M. Antonietti and F. Vilela, Angew. Chem. Int. Ed., 2013, 52, 1432-1436.

11 C. Yang, B. C. Ma, L. Zhang, S. Lin, S. Ghasimi, K. Landfester,
K. A. I. Zhang and X. Wang, Angew. Chem. Int. Ed., 2016, 55, 9202-9206.
12

13

14

15

16
X. Zong, X. Miao, S. Hua, L. An, X. Gao, W. Jiang, D. Qu, Z. Zhou, X. Liu and Z. Sun, Appl. Catal. B Environ., 2017, 211, 98-105.

M. Sachs, R. S. Sprick, D. Pearce, S. A. J. Hillman, A. Monti, A. A. Y. Guilbert, N. J. Brownbill, S. Dimitrov, X. Shi, F. Blanc, M. A. Zwijnenburg, J. Nelson, J. R. Durrant and A. I. Cooper, Nat. Commun., 2018, 9, 4968.

R. S. Sprick, C. M. Aitchison, E. Berardo, L. Turcani, L. Wilbraham, B. M. Alston, K. E. Jelfs, M. A. Zwijnenburg and A. I. Cooper, J. Mater. Chem. A, 2018, 6, 11994-12003. R. S. Sprick, L. Wilbraham, Y. Bai, P. Guiglion, A. Monti, R. Clowes, A. I. Cooper and M. A. Zwijnenburg, Chem. Mater., 2018, 30, 5733-5742.

A. Vogel, M. Forster, L. Wilbraham, C. L. Smith, A. J. Cowan, M. A. Zwijnenburg, R. S. Sprick, A. I. Cooper, Faraday Discuss., 2019,215, 84-97.

R. S. Sprick, J. X. Jiang, B. Bonillo, S. Ren, T. Ratvijitvech, P. Guiglion, M. A. Zwijnenburg, D. J. Adams and A. I. Cooper, J. Am. Chem. Soc., 2015, 137, 3265-3270.

L. Li, Z. Cai, Q. Wu, W. Y. Lo, N. Zhang, L. X. Chen and L. Yu, J. Am. Chem. Soc., 2016, 138, 7681-7686.

L. Li, W. Y. Lo, Z. Cai, N. Zhang and L. Yu, Macromolecules, 2016, 49, 6903-6909.

Y. S. Kochergin, D. Schwarz, A. Acharjya, A. Ichangi, R. Kulkarni, P. Eliášová, J. Vacek, J. Schmidt, A. Thomas and M. J. Bojdys, Angew. Chem. Int. Ed., 2018, 57, 14188-14192. R. S. Sprick, Y. Bai, A. A. Y. Guilbert, M. Zbiri, C. M. Aitchison, L. Wilbraham, Y. Yan, D. J. Woods, M. A. Zwijnenburg and A. I. Cooper, Chem. Mater., 2019, 31, 305-313.

L. Stegbauer, K. Schwinghammer and B. V. Lotsch, Chem. Sci., 2014, 5, 2789-2793.

V. S. Vyas, F. Haase, L. Stegbauer, G. Savasci, F. Podjaski, C. Ochsenfeld and B. V Lotsch, Nat. Commun., 2015, 6, 8508. F. Haase, T. Banerjee, G. Savasci, C. Ochsenfeld, B. V. Lotsch, S. Takahashi, M. Addicoat, M. E. El-Khouly, T. Nakamura, S. Irle, S. Fukuzumi, A. Nagai and D. Jiang, Faraday Discuss., 2017, 162, 165-169.

X. Wang, L. Chen, S. Y. Chong, M. A. Little, Y. Wu, W.-H. Zhu, R. Clowes, Y. Yan, M. A. Zwijnenburg, R. S. Sprick and A. I. Cooper, Nat. Chem., 2018, 10, 1180-1189. E. Jin, Z. Lan, Q. Jiang, K. Geng, G. Li, X. Wang and D. Jiang, Chem, 2019, 5, 1632-1647.

J. Bi, W. Fang, L. Li, J. Wang, S. Liang, Y. He, M. Liu and L. Wu, Macromol. Rapid Commun., 2015, 36, 1799-1805. C. B. Meier, R. S. Sprick, A. Monti, P. Guiglion, J. S. M. Lee, M. A. Zwijnenburg and A. I. Cooper, Polymer, 2017, 126, 283-290.

L. Guo, Y. Niu, H. Xu, Q. Li, S. Razzaque, Q. Huang, S. Jin and B. Tan, J. Mater. Chem. A, 2018, 6, 19775-19781. C. B. Meier, R. Clowes, E. Berardo, K. E. Jelfs, M. A. Zwijnenburg, R. S. Sprick and A. I. Cooper, Chem. Mater. 2019, 31, 8830-8838.

S. Yanagida, A. Kabumoto, K. Mizumoto, C. Pac and K. Yoshino, J. Chem. Soc. Chem. Commun., 1985, 474-475. 

Sprick and A. I. Cooper, J. Am. Chem. Soc., 2019, 141, 9063-9071.

33 Z.-A. Lan, G. Zhang, X. Chen, Y. Zhang, K. A. I. Zhang and X. Wang, Angew. Chem. Int. Ed., 2019, 58, 10236-10240.

34 R. S. Sprick, M. Hoyos, J. J. Morrison, I. M. Grace, C. Lambert, O. Navarro and M. L. Turner, J. Mater. Chem. C, 2013, 1, 3327-3336.

35 F. Caffy, N. Delbosc, P. Chávez, P. Lévêque, J. FaureVincent, J.-P. Travers, D. Djurado, J. Pécaut, B. Grévin, N. Lemaitre, N. Leclerc and R. Demadrille, Polym. Chem., 2016, 7, 4160-4175.

36 V. H. K. Fell, A. Mikosch, A.-K. Steppert, W. Ogieglo, E. Senol, D. Canneson, M. Bayer, F. Schoenebeck, A. Greilich and A. J. C. Kuehne, Macromolecules, 2017, 50, 2338-2343. D. J. Woods, R. S. Sprick, C. L. Smith, A. J. Cowan and A. I. Cooper, Adv. Energy Mater., 2017, 7, 1700479. P. Guiglion, C. Butchosa and M. A. Zwijnenburg, J. Mater. Chem. A, 2014, 2, 11996-12004.

39 P. Guiglion, A. Monti and M. A. Zwijnenburg, J. Phys. Chem. C, 2017, 121, 1498-1506.

40 A. D. Becke, J. Chem. Phys., 1993, 98, 5648-5652.

41 P. J. Stephens, F. J. Devlin, C. F. Chabalowski and M. J. Frisch, J. Phys. Chem., 1994, 98, 11623-11627. 